\title{
Temporal differences in food abundance promote coexistence between two congeneric passerines
}

\author{
Thor Veen · Ben C. Sheldon · Franz J. Weissing • \\ Marcel E. Visser · Anna Qvarnström • \\ Glenn-Peter Sætre
}

Received: 8 April 2009 / Accepted: 9 December 2009 / Published online: 31 December 2009

(C) The Author(s) 2009. This article is published with open access at Springerlink.com

\begin{abstract}
Many related species share the same environment and utilize similar resources. This is surprising because based on the principle of competitive exclusion one would predict that the superior competitor would drive the other species to extinction; coexistence is only predicted if interspecific competition is weaker than
\end{abstract}

Communicated by Markku Orell.

T. Veen $\cdot$ F. J. Weissing

Theoretical Biology Group,

Centre for Ecological and Evolutionary Studies,

University of Groningen, Kerklaan 30,

9751 NN Haren, The Netherlands

T. Veen · G.-P. Sætre

Department of Biology, Centre for Ecological and Evolutionary

Synthesis, University of Oslo, P.O. Box 1066,

Blindern, 0316 Oslo, Norway

T. Veen $(\bowtie)$

Centre for Ecology and Conservation, School of Biosciences,

University of Exeter, Cornwall Campus,

Penryn TR10 9EZ, UK

e-mail: t.veen@exeter.ac.uk

B. C. Sheldon

Edward Grey Institute, Department of Zoology,

University of Oxford, South Parks Road,

Oxford OX1 3PS, UK

M. E. Visser

Netherlands Institute of Ecology (NIOO-KNAW),

P.O. Box 40, 6666 ZG Heteren, The Netherlands

\section{A. Qvarnström}

Animal Ecology, Department of Ecology and Evolution, Uppsala University, Norbyvägen 18D,

75236 Uppsala, Sweden intraspecific competition. Interspecific competition is frequently reduced by differential resource use, resulting in habitat segregation. In this paper, we use the closely related collared and pied flycatcher to assess the potential of habitat differences to affect interspecific competition through a different mechanism, namely by generating temporal differences in availability of similar food resources between the two species. We found that the tree species composition of the breeding territories of the two species differed, mainly by a higher abundance of coniferous species around nest-boxes occupied by pied flycatchers. The temporal availability of caterpillars was measured using frass traps under four deciduous and two coniferous tree species. Deciduous tree species showed an early and narrow peak in abundance, which contrasted with the steady increase in caterpillar abundance in the coniferous tree species through the season. We subsequently calculated the predicted total caterpillar biomass available in each flycatcher territory. This differed between the species, with biomass decreasing more slowly in pied flycatcher territories. Caterpillar biomass is strongly correlated with the reproductive success of collared flycatchers, but much less so with pied flycatchers. However, caterpillar availability can only partly explain the differences in seasonal decline of reproductive success between the two species; we discuss additional factors that may contribute to this species difference. Overall, our results are consistent with the suggestion that minor habitat differences between these two species may contribute to promoting their coexistence.

Keywords Habitat characterisation - Sympatric species . Ficedula albicollis $\cdot$ Ficedula hypoleuca $\cdot$ Species interactions 


\section{Introduction}

A striking pattern in nature is the apparent coexistence of ecologically similar species. The principle of competitive exclusion would predict that differences in competitive ability, even if relatively small, should lead to the extinction of the less competitive species (Hardin 1960). This appears not to be the case in many natural systems and various different explanations have been put forward, of which niche differentiation is particularly influential (e.g. Chesson 2000; Wright 2002). The basic idea is that different species specialise on, for example, different food resources and thereby decrease the strength of interspecific competition. The observed differences are often rather small and may appear, at first sight, unlikely to reduce interspecific competition to such an extent that competitive exclusion is avoided altogether (e.g. Chesson 2000 and references therein). One explanation for this pattern, and the focus of the present study, is that the observed differences between the species may have several different small effects, which combine together to reduce interspecific competition.

Habitat specialisation is frequent among ecologically similar bird species (e.g. Cody 1978; Forstmeier et al. 2001; Hudman and Chandler 2002). Differences in habitat occupation are predicted to decrease the frequency of interactions between heterospecific individuals and thereby to reduce competition intensity. A second, much less well studied effect of habitat differences is the influence these could have on the temporal availability of food in the different habitats. Food availability is known to be an important factor influencing reproductive success, and birds typically match periods of high energetic demands of the nestlings with those of greatest food availability (Perrins 1970). The aim of this study is to investigate how habitat differences between two closely related passerines affect the temporal food abundance in their breeding territories and ultimately their reproductive success.

The closely related collared (Ficedula albicollis) and pied flycatcher (Ficedula hypoleuca) provide one representative example of an ecologically similar species pair with overlapping breeding ranges. Both species prefer deciduous over coniferous habitat (e.g. Lundberg et al. 1981; Lundberg and Alatalo 1992; Huhta et al. 1998). In the Czech Republic, previous work has shown that the collared flycatcher is competitively dominant and the pied flycatcher is forced through interspecific competition to (potentially) less favourable breeding locations at higher altitudes (Sætre et al. 1999a, b). A recent study, however, indicates that the differences in habitat occupation might be partly explained by differences in habitat preferences between the two species (Adamik and Bureš 2007; contra Alerstam et al. 1978; Lundberg and Alatalo 1992). Regardless of how it arises, differences in habitat occupation result in spatial segrega- tion between the species. But how can pied flycatchers persist in such an apparently unfavourable environment? The pied flycatcher is predicted to be better adapted to harsher environments because the allopatric breeding environment of this species includes colder regions with more coniferous habitats compared with that of the collared flycatcher (Sætre et al. 1999a). Such adaptation might be so strong that the pied flycatcher may actually prefer this habitat type (Adamik and Bureš 2007). This claim remains controversial as deciduous trees harbour a considerably richer food resource (e.g. van Balen 1973; Lundberg and Alatalo 1992) and Adamik and Bureš (2007) found higher prey catching rates in deciduous trees.

Flycatchers might be better adapted to finding food in their native environment, but specialization on different food resources seems unlikely to be very important for these species as their diets are flexible and dietary overlap between the species is very high (Lundberg and Alatalo 1992; Bureš 1995; Wiley et al. 2007). Food availability is another important factor which is known to influence the reproductive success of flycatchers (Török and Tóth 1988; Siikamäki 1998). It remains untested whether habitat differences result in differences in food abundance between breeding territories of the two species and how this might affect their reproductive success. If differences in food abundance benefit the reproductive success of the competitively subordinate species (pied flycatcher), it could counteract the negative fitness effects of interspecific competition on reproductive success, and thereby facilitate coexistence.

In this study we test the hypothesis that habitat differences between the closely related collared and pied flycatcher might lead to temporal differences in food abundance. This difference in food abundance is predicted to differentially affect their reproductive success, which would facilitate their coexistence. This hypothesis is tested by linking habitat characteristics of breeding territories of both species with availability of a major food resource for their offspring (caterpillars) on their sympatric breeding grounds on the Baltic Islands of Gotland and Öland (Sweden).

Caterpillars account for a substantial part of the food items provided to the nestlings; $36.1 \%(\mathrm{SD}=24.7)$ for the pied flycatcher and $25.4 \%(\mathrm{SD}=13.4)$ for the collared flycatcher [data extracted from Cramp and Perrins (1993)].

The predicted difference in abundance through the breeding season of caterpillars between deciduous and coniferous trees (e.g. van Balen 1973; Lundberg and Alatalo 1992; Eeva et al. 1997) linked with the habitat differences found between the species (Alerstam et al. 1978) could lead to temporal differences in food availability in territories for the two species. The potential importance of breeding territory characteristics on reproductive success has been suggested in previous studies. Veen et al. (2001) 
found that the reproductive success of broods with a male pied flycatcher parent was higher late in the season compared to pure collared flycatcher pairs. A recent study showed that this can, at least partly, be attributed to differences in territory characteristics (Wiley et al. 2007). Our approach requires us to take three steps. As these are sequential steps, we will present the methods and results for each step individually within the "Results". In the first section (habitat differences) we set out to corroborate previously described habitat differences (Alerstam et al. 1978) on Öland. In the next section (predicted food abundance) we quantify food availability under six dominant tree species by measuring frass fall to quantify temporal patterns of caterpillar availability. This measure was combined with habitat data to get an estimate of total available caterpillar biomass during the nestling period in breeding territories. The last section (reproductive success) starts with testing whether differences in reproductive success between the two species previously found on Gotland are also present on Öland (as we use data from both locations in this study). Subsequently we investigate whether or not the predicted food abundance explains the patterns found in reproductive success. This was done in two ways: one detailed approach that used breeding territory characteristics individually (only 2 years of data available), and a more general method (analysing 7 years of data).

\section{Materials and methods}

\section{Study species}

Collared and pied flycatchers are migratory passerine bird species. The breeding range of the collared flycatcher covers south-eastern Europe and extends into Ukraine and Russia, whereas that of the pied flycatcher occupies forested areas of most of western and northern Europe and extends further north and east into Russia (Cramp and Perrins 1993). Phylogeographic studies indicate that after the last glaciation period, the species' ranges expanded north and eastwards, along with the expanding forests, from their respective glaciation refugia on the Iberian (pied) and Italian (collared) peninsulas and met in central Europe, and more recently (approximately 150 years ago), on the Baltic islands of Gotland and Öland (e.g. Sætre et al. 2003). We studied flycatcher populations breeding in nest-boxes. In contrast to central Europe where the two species are partly separated by altitude (Sætre et al. 1999a) altitudinal gradients are effectively absent on the Baltic Islands. During the breeding season standard reproductive data and parental identities were recorded for all breeding pairs as part of an ongoing long-term study. In the context of temporal differences in food abundance it is important to mention that the mean laying date of the pied flycatcher was almost 3 days later compared to the collared flycatcher (Qvarnström et al. 2005). In cases of uncertainty over species identity, this was determined using species-specific differences in single nucleotide polymorphisms, as described elsewhere (e.g. Sætre et al. 2003).

\section{Statistical procedure}

In order to control for differences between years in seasonality, we represent all dates relative to the mean egg-laying date, calculated for each year separately, with data for both flycatcher species combined. Laying dates corrected for this measure are referred to as the 'adjusted date'.

The statistical analyses were conducted in two steps as described in Crawley (2007). First, variables were excluded in a backwards-stepwise fashion based on their $P$-value (highest value removed first). Second, for each removed variable, the reduced model was compared with the original model using ANOVAs (with the appropriate test statistic). If model reduction did not significantly reduce the model fit, the next least significant variable was excluded. The final model is the model where further reduction significantly reduced model fit. Model fit was compared using $F$-test statistics for generalized linear models (GLMs) with a quasi Poisson distribution and an ANOVA with $\chi^{2}$ distribution for GLMs with a binary response variable and analyses of covariance (ANCOVAs; Crawley 2007). The test statistics of both tests are presented in tables and the $P$-values of the model selection steps. (Note that for only one of all variables included in the final model the $P$-value is presented, namely the variable with the highest $P$-value (and therefore the one which was excluded in the subsequent reduced model). The analyses were performed using $\mathrm{R}(\mathrm{R}$ Development Core Team 2008).

\section{Results}

\section{Habitat differences}

Measuring the important habitat characteristics of a flycatcher's breeding territory is not straightforward, as this should be done according to how an individual flycatcher utilises its surroundings, of which comparatively little is known. One method used is to measure the vegetation in a circle around the point of interest (e.g. Hudman and Chandler 2002), which assumes that this area accurately reflects the feeding habitat. This method neglects distant but potentially important food resources (e.g. a large tree). We therefore preferred to use the 'angle count' method, widely used in forestry (and also for ecological questions e.g. Edwards and Collopy 1988; Huhta et al. 1998). This 
method uses the relative size of the tree trunks assessed from a point in the woodland (in our case the nest-box) to get an estimate of the 'basal area' of the trees. Inclusion of a tree in the count depends on the trunk size of the tree and its proximity to the sampling point, i.e. at a certain distance, small trees will not be included but larger ones will be. In the field, a relascope (a measuring scale kept at a fixed distance from the eye) was used to conduct the measurements, while standing next to the nest-box. Each individual tree was classified, based on the size of the trunk relative to the scale, into one of three categories and assigned a value accordingly; (1) too small (value 0), (2) medium sized (value 0.5 ) and (3) large (value 1). For each flycatcher territory measured, all basal area values were summed for each tree species. In the few cases where understorey vegetation blocked the view, the size of the obscured trunks was measured by changing the angle while keeping the same distance. A prerequisite for a good estimator of caterpillar abundance is that it needs to reflect the quantity of leaves (the food resource for caterpillars), which is the case for the basal area as this measure is highly correlated with the crown volume (Verner and Larson 1989).

The breeding territories for habitat measurements were selected by matching collared flycatcher and pied flycatcher breeding pairs within the same year by laying date. Pied flycatchers are much more abundant on Öland compared to
Gotland and due to time limitations we collected habitat measures only from Öland. Unfortunately, the data needed for reproductive success analyses (see below) were not available for all broods. Broods for which data were lacking were excluded from the analysis in order to have a consistent dataset for all analyses. We included adjusted date as an explanatory variable to check for potential temporal effects.

A total of 16 tree species could be identified to species; other trees could only be assigned to genus [alder (Alnus sp.), poplar (Populus sp.), rowan (Sorbus sp.), and elm (Ulmus sp.)]. This could potentially bias the influence of certain tree species or genera [e.g. hard-to-identify species would be all lumped into a single category (genus) instead of several (species)]. To avoid such biases we pooled all data at the level of the genus (hereafter referred to by their common name). Tree species with an occurrence of less than $1 \%$ of the total basal area were amalgamated into one category (termed 'other'). This category consisted of the following species: beech (Fagus sylvatica), common juniper (Juniperus communis), lime tree (Tilia platyphyllos), Norway maple (Acer platanoides), wild apple (Malus sylvestris) and 'unidentified trees'. The mean basal area and SD of the 11 groups are presented in Table 1. Single hazel 'trees' typically consisted of many small trunks due to intense coppicing. All trunks combined were used to estimate the basal area in a similar way as for the other species.
Table 1 Generalized linear models (GLM) with binary response variable of the effect of year, adjusted date and (1) the basal areas of all 11 tree species, (2) the basal areas of coniferous and deciduous species on the presence/absence of collared flycatchers. [Note that absence (0) indicates the presence of a pied flycatcher.] Variables included in the final model are in bold

Significant $P$-values are in italic

\begin{tabular}{|c|c|c|c|c|c|c|}
\hline \multirow[t]{2}{*}{ Source } & \multicolumn{2}{|c|}{ Flycatcher species } & \multirow{2}{*}{$\begin{array}{l}\text { GLM } \\
t\end{array}$} & \multicolumn{3}{|c|}{ Model selection } \\
\hline & Collared & Pied & & $d f$ & $F$ & $P$ \\
\hline \multicolumn{7}{|c|}{ Basal areas of all 11 tree species } \\
\hline Intercept & & & -0.241 & 1,62 & & \\
\hline Adjusted date & & & 1.533 & 1,61 & 2.551 & 0.115 \\
\hline Year & & & 0.982 & 1,60 & 0.980 & 0.326 \\
\hline Poplar & $0.1(0.4)$ & $1.4(3.9)$ & -0.509 & 1,54 & 0.311 & 0.579 \\
\hline Rowan & $0.3(0.7)$ & $0.2(0.5)$ & 1.137 & 1,56 & 1.440 & 0.235 \\
\hline Spruce & $0.3(1.0)$ & $0.3(0.9)$ & -0.036 & 1,52 & 0.001 & 0.972 \\
\hline Ash & $2.4(4.2)$ & $1.7(1.8)$ & 0.972 & 1,58 & 1.055 & 0.309 \\
\hline Elm & $0.7(1.4)$ & $1.6(3.4)$ & -0.265 & 1,53 & 0.072 & 0.790 \\
\hline Hazel & $5.0(6.7)$ & $1.2(2.3)$ & 2.270 & 1,62 & & \\
\hline Birch & $2.5(3.5)$ & $1.5(3.2)$ & 0.931 & 1,59 & 0.904 & 0.346 \\
\hline Alder & $2.9(4.9)$ & $1.3(3.1)$ & 1.732 & 1,62 & & \\
\hline Pine & $0.2(0.7)$ & $3.0(4.9)$ & -1.661 & 1,62 & 10.042 & 0.002 \\
\hline Oak & $2.8(4.2)$ & $2.1(3.4)$ & 1.204 & 1,57 & 1.499 & 0.226 \\
\hline Other & $0.4(1.3)$ & $0.3(0.54)$ & 0.718 & 1,55 & 0.610 & 0.438 \\
\hline \multicolumn{7}{|c|}{ Basal areas of coniferous and deciduous species } \\
\hline Intercept & & & 2.594 & 1,64 & & \\
\hline Year & & & 1.468 & 1,61 & 2.211 & 0.142 \\
\hline Adjusted date & & & 1.458 & 1,63 & 2.216 & 0.142 \\
\hline Deciduous & $17.0(5.9)$ & $12.3(7.6)$ & 1.515 & 1,62 & 2.416 & 0.125 \\
\hline Coniferous & $0.5(1.2)$ & $3.4(5.1)$ & -2.392 & 1,64 & 11.995 & $<0.001$ \\
\hline
\end{tabular}


Previous work has suggested that an important difference between the two flycatcher species is that pied flycatchers occupy more coniferous habitats compared to collared flycatchers (Sætre et al. 1999a). We tested whether this is the case on Öland by calculating the summed basal areas of all the coniferous and deciduous tree genera for each territory (thus reducing 11 tree genera into two tree groups). A GLM with a binary response variable (the presence/absence of a collared flycatcher; note that in this analysis the absence of a collared means the presence of a pied) and logit link function was used to test for differences between the two flycatcher species. As explanatory variable we included the combined basal area of all coniferous and deciduous tree species for each measured territory. Furthermore we included adjusted date and year [as habitat choice might change through the season or differ between years due to e.g. differences in interspecific competition (Sætre et al. 1999a, b)]. Model comparison was done using ANOVAs with a $\chi^{2}$ distribution (Crawley 2007).

\section{Results habitat differences}

Only the combined basal area of the coniferous tree species remained significant in the final model (Table 1). The mean basal area of the deciduous tree species differed very little between the species, but the basal area of coniferous tree species was significantly higher in pied flycatcher territories (Table 1).

Next, a similar statistical approach was used to test for differences at a more detailed level (tree genera). The full model included the 11 tree genera (including 'other'), year and adjusted date. The final model consisted of alder, hazel and pine. Further model reduction by excluding pine resulted in a significantly reduced model fit and this term was therefore retained. An overview of the test statistics and the abundance of the different tree genera are given in Table 1.

We conclude that pied flycatcher territories have significantly more coniferous tree species compared to collared flycatcher territories. This difference is also present at the level of tree genera, although less strongly. These results are in line with earlier studies (Alerstam et al. 1978; Lundberg and Alatalo 1992).

Predicted food abundance

\section{Caterpillar abundance}

In order to assess the potential effect of the differences in habitat found in the previous section on reproductive success, we first quantified food abundance in different tree species through the breeding season. Caterpillars are one of the main food items fed to nestlings in both species (Cramp and Perrins 1993; Bureš 1995; Wiley et al. 2007). The phenology of caterpillar abundance was measured indirectly by collecting their faecal pellets (frass) in so-called frass nets. A frass net was positioned underneath a tree, roughly $1 \mathrm{~m}$ from the trunk, and consisted of a $0.25-\mathrm{m}^{2}$ funnel-shaped piece of cheese cloth mounted on a metal frame (Tinbergen 1960; van Balen 1973; Visser et al. 2006). In the period 2002-2004, nineteen frass traps were placed on Gotland under the same individual trees. The traps were placed in two predominantly deciduous woodlands (approximately $5 \mathrm{~km}$ apart) under four deciduous [seven oak (Quercus sp.), two birch (Betula pendula), four hazel (Corylus avellana) and one ash (Fraxinus excelsior)] and two coniferous tree species [two pine (Pinus sp.) and three spruce (Picea sp.)]. We believe that these temporal patterns of caterpillar abundance are representative for Öland, where the habitat data were collected, given its close proximity (approximately $50 \mathrm{~km}$ apart), similar habitat composition (Alerstam et al. 1978) and small differences in timing of breeding of the focal bird species (A. Qvarnström, unpublished).

The tree species and the number of individuals sampled of each species were chosen at the start of the study in such a way as to reflect the natural abundance of tree species in the study areas as closely as possible. Individual trees were selected in close proximity to each other (less than $50 \mathrm{~m}$ ) to allow for easy access. Frass traps were placed early in the season, the sampling started before bud burst, and the traps were emptied every 4 th day for 7 weeks unless the weather conditions did not allow this. The time of sampling was recorded in days, and date expressed as days from 1 May (1 May =1) and numbered consecutively afterwards. Both rain and temperature can influence the (measured) production of frass (Tinbergen and Dietz 1994). The disintegrative effect of rain on frass was reduced by covering the traps during heavy rain. The effect of temperature was accounted for when transforming frass weight to caterpillar biomass using the approach described in Tinbergen and Dietz (1994). Samples were dried indoors and stored at room temperature. The frass was separated from litter using Retsch test sieves (smallest sieve $600 \mu \mathrm{m}$ ) and weighed to an accuracy of $0.1 \mathrm{mg}$. For each individual trap, the frass weight of each sampling event (normally ten per season) was divided by the duration of the sampling period (normally 4 days), to get frass weight/trap per day. Because this is an average over the sampling period, we used the midpoint between two subsequent checks as the sampling date (hereafter 'mid-sample date').

The amount of frass collected depends on the size of the tree, i.e. the volume of leaves in a column above the trap. The height of the trees varied considerably [mean height and SD: $19.64 \mathrm{~m}$ (5.40)]. Crown height was estimated by using a combination of the height of the tree (measured using a Suunto PM-5/400 PC clinometer) and standardized 


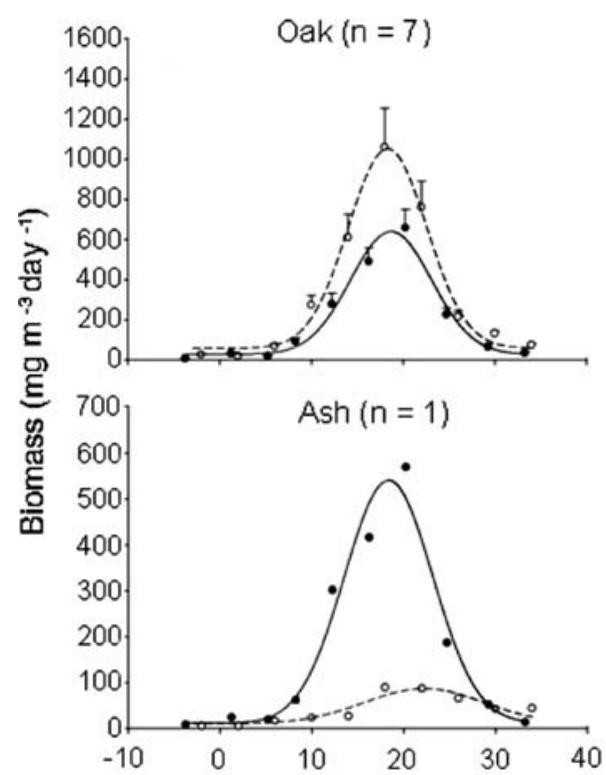

Fig. 1 Predicted caterpillar biomass $\left(\mathrm{mg} \mathrm{m}^{-3}\right)$ through the breeding season (adjusted date), based on measures of frass fall collected in traps and adjusted for tree size. The mean biomass and SE of all traps for each measuring interval are presented. Each of the six tree species is depicted (solid circles indicate 2003, open circles indicate 2004);

pictures (to measure the distance between the top and the lowest leaf-bearing branches of the tree). Unfortunately, several trees were logged before height measurements could be taken. In such cases the height of a similar-sized tree within $10 \mathrm{~m}$ of the logged one was used. For each individual tree used for frass sampling, the frass biomass was multiplied by 4 (to get biomass per $\mathrm{m}^{2}$ ) and subsequently divided by the crown height to standardise the frass biomass for crown size to get biomass per $\mathrm{m}^{3}$ tree crown. (Note that this will not alter the temporal pattern in food abundance.)

\section{Results caterpillar abundance}

The temporal variation of caterpillar biomass on deciduous tree species had a clearly unimodal distribution and could be approximated by a Gaussian curve [mean $R^{2}$ and SD: 0.93 (0.04); Fig. 1]. The coniferous species (spruce and pine) were expected to differ from the deciduous species by having a much later peak date (van Balen 1973). Our sampling period was not long enough to capture the declining part of the frass curve properly, and hence the $R^{2}$ of the fitted Gaussian curve is lower [0.78 (0.10)]. The data as presented in Fig. 1 confirm the differences between coniferous and deciduous species in temporal abundance. Furthermore there is a clear difference between tree species in caterpillar biomass, with oak having the highest values and the coniferous species the lowest. Within species, however, there is considerable variation between different trees

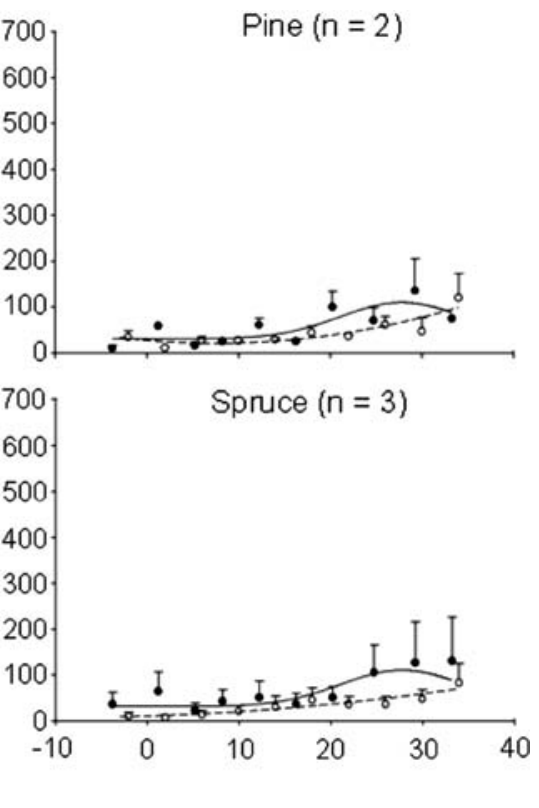

note that a different biomass scale is used for oak. The SE for the last measurement of pine in 2003 is missing as the measurement of one trap failed. Data from 2002 look very similar but are not plotted as this year is only used in the last section of the "Results"

mainly in the height of the peak biomass, as indicated by the large error bars.

\section{Predicted food abundance in breeding territories}

The habitat measurements can be combined with the caterpillar biomass of six common tree species to calculate the available caterpillar biomass for territories of both flycatcher species through the breeding season. As food is of prime importance during nestling feeding, we calculated the total caterpillar biomass available during this period. The hatching date is on average 19 days after initiation of egg laying and nestlings stay on average 15 days in the nest (unpublished data). Available caterpillar biomass is represented by the area under the caterpillar biomass curve during the nestling period (Fig. 2). This measure was derived by numerically calculating the integral over the nestling period of the fitted Gaussian caterpillar biomass curve, which was subsequently multiplied by the basal area of the tree species, to get the predicted caterpillar biomass of a given tree species during the nestling period. This was conducted for all six tree species and summed to get the total predicted caterpillar biomass for a territory in a given year for a nest with a given hatching and fledging date. Note that this biomass measure incorporates differences in the relative abundance of tree species but does not calculate the absolute caterpillar biomass (as this requires using crown volume). Using the basal area or tree crown volume should give the same qualitative results as both are strongly 


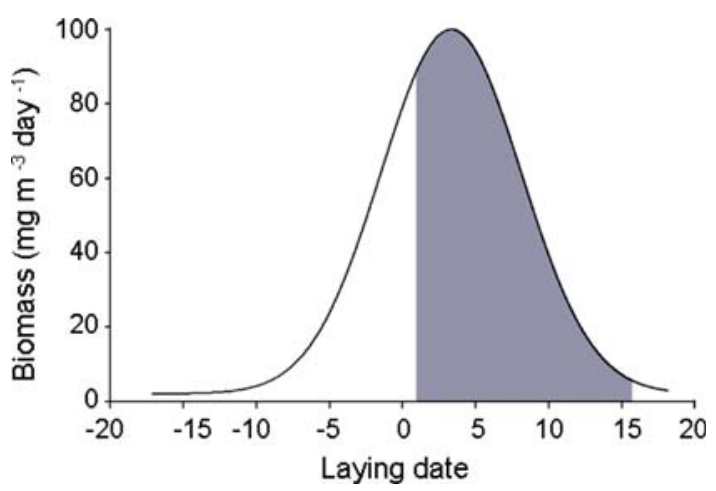

Fig. 2 Representation of the total caterpillar biomass (grey area) in a hypothetical biomass curve of a brood with hatching date 1 and fledging date 16. Note that the period over which the integral is taken is always 15 days (the nestling period)

correlated (Verner and Larson 1989). Reproductive data were available for 2003 and 2004.

To test for differences between the two flycatcher species in food abundance during their chick-rearing period, we conducted an ANOVA with the total predicted biomass as response variable and species and year as explanatory factors. To test for seasonal differences in food abundance, we conducted an ANCOVA including species, year, adjusted date as covariate and an interaction between species and adjusted date. Caterpillar biomass was log transformed to comply with normality requirements. Model comparison was done using an ANOVA with $\chi^{2}$ distribution.

\section{Results predicted food abundance}

The two flycatcher species did not differ significantly in caterpillar biomass $\left[F_{1,64}=1.653, \quad P=0.203\right.$; year was excluded in the first step $\left.\left(F_{1,63}=0.008, P=0.930\right)\right]$.

Year was not significant in the test for seasonal differences in caterpillar biomass and was excluded from the final model. Further model reduction did not improve the model fit. There was a significant interaction between adjusted date and species (Table 2). Adding adjusted date squared to the model did not increase model fit. Figure 3 shows that collared flycatchers have a significantly steeper decline in predicted food abundance through the season compared to the pied flycatcher. We conclude that food availability differs between territories of the two species through the breeding season in 2003-2004, although the overall explanatory power of this model is low $\left(R^{2}=0.22\right)$.

Reproductive success

\section{Reproductive success on Öland}

As habitat measurements and reproductive data used for this study were collected on Öland, we first validate
Table 2 An analysis of covariance (ANCOVA) testing the effect of year, adjusted date, species and an interaction (adjusted date $\times$ species) on predicted caterpillar biomass availability. Variables included in the final model are presented in bold

\begin{tabular}{|c|c|c|c|c|}
\hline \multirow[t]{2}{*}{ Source } & \multirow{2}{*}{$\begin{array}{l}\text { ANCOVA } \\
t\end{array}$} & \multicolumn{3}{|c|}{ Model selection } \\
\hline & & $d f$ & $F$ & $P$ \\
\hline Intercept & 72.012 & 1.62 & & \\
\hline Year & -0.660 & 1.61 & 0.436 & 0.512 \\
\hline Adjusted date (AD) & -3.974 & 1.62 & & \\
\hline Species (S) & -1.638 & 1.62 & & \\
\hline $\mathbf{A D} \times \mathbf{S}$ & 2.949 & 1.62 & 8.698 & 0.004 \\
\hline
\end{tabular}

Significant $P$-values in italic

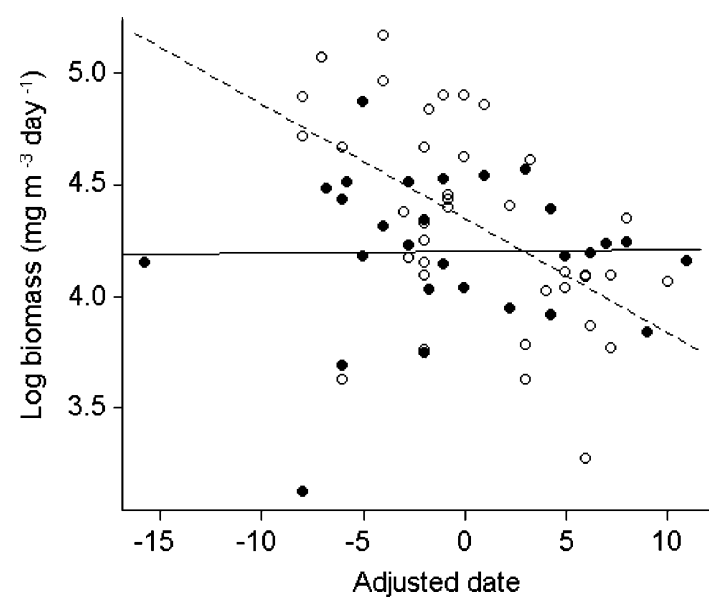

Fig. 3 Log caterpillar biomass for collared (open circles) and pied flycatcher (solid circles) territories against the adjusted date of the brood. Fitted curves for collared (dashed) and pied flycatchers (solid) were derived from the analysis of covariance as presented in Table 2

whether the differences in reproductive success-a much steeper seasonal decrease for collared flycatcher broods compared to pied flycatcher broods on Gotland-were also present on Öland. We used data on reproductive success (number of fledged young) of all pure collared (591) and pied flycatcher pairs (30) available from 2002 to 2007. A GLM for count data [quasi Poisson distribution (data were underdispersed) and log link function] was used with the number of fledged young per brood as response variable. An interaction between adjusted date and species was included to test for seasonal differences in reproductive success between the two species. Models were compared using an $F$-test statistic for a GLM with quasi Poisson distribution (Crawley 2007).

Only year was not significant and excluded. Removal of the interaction between species and adjusted date significantly reduced model fit and was therefore retained (see Table 3; Fig. 4 for the direction of the interaction). This pattern cannot be explained by species differences in 
Table 3 GLM with quasi Poisson distribution of the effect of year, adjusted date, species (collared/pied flycatcher) and an interaction between them on the reproductive success (number of fledglings per brood). Variables included in the final model are in bold

\begin{tabular}{lrlcl}
\hline Source & GLM & \multicolumn{4}{l}{ Model selection } \\
\cline { 2 - 5 } & \multicolumn{1}{l}{$t$} & $d f$ & $F$ & $P$ \\
\hline Intercept & 89.564 & 1,617 & & \\
Year & -0.886 & 1,616 & 0.785 & 0.376 \\
Adjusted date (AD) & -6.243 & 1,617 & & \\
Species (S) & 0.438 & 1,617 & & \\
AD $\times$ S & 3.515 & 1,617 & 12.452 & $<0.001$ \\
\hline
\end{tabular}

Significant $P$-values are in italic

seasonal clutch size change as a three-way interaction between clutch size, adjusted date and species added to the above described analysis was non-significant and excluded in the first model selection step $\left(F_{1,612}=0.0635\right.$, $P=0.801)$. We conclude that the temporal difference in reproductive success between collared and pied flycatchers was also present on Öland.

\section{Predicted caterpillar abundance and reproductive success}

Food is important for the growth and fledging success of the chicks. Consequently, estimated food abundances is expected to influence the reproductive success of both species. We thus predicted that when the food availability $x$ species interaction is added to the analysis of the reproductive success differences (2003-2004), the significant interaction between species and adjusted date should disappear.

This analysis showed that the interaction between species and log caterpillar biomass disappears first (Table 4), but the adjusted date $\times$ species interaction is subsequently also excluded from the model. The final model contains year and species. In the 2003-2004 subset there is no negative relationship between the number of fledged young from collared flycatcher broods and adjusted date (thus the
Table 4 GLM with quasi Poisson distribution testing for the effect of year, adjusted date, log caterpillar biomass, species and interactions between adjusted date and species and between log caterpillar biomass and species on the reproductive success of collared and pied flycatchers. Variables included in the final model are presented in bold

\begin{tabular}{lrrrr}
\hline Source & GLM & \multicolumn{3}{c}{ Model selection } \\
\cline { 3 - 5 } & \multicolumn{1}{c}{$t$} & $d f$ & $F$ & $P$ \\
\hline Intercept & -2.310 & 1,63 & & \\
Year & 2.318 & 1,63 & 5.560 & 0.021 \\
Adjusted date (AD) & -0.960 & 1,62 & 0.923 & 0.341 \\
Log caterpillar biomass (CB) & 0.467 & 1,61 & 0.219 & 0.641 \\
Species (S) & 2.430 & 1,63 & & \\
AD $\times$ S & -0.564 & 1,60 & 0.318 & 0.575 \\
CB $\times$ S & -0.247 & 1,59 & 0.139 & 0.711 \\
\hline
\end{tabular}

Significant $P$-values are in italic

interaction between adjusted date and species is absent) which limits the possibility to draw general conclusions.

\section{All reproductive success data}

So far the analyses have been conducted at the level of each individual territory using unique habitat characteristics and the caterpillar phenologies for the year of breeding. This approach has the advantage of retaining detailed information, but is only available for 2 years of reproductive data. In this section we explore the relation between reproductive success of 7 years and food availability. To conduct this analysis we used the average habitat characteristics of each flycatcher species (see Table 1). Caterpillar phenologies were only available for 3 (2002-2004) of the 7 years. This was circumvented by calculating the average caterpillar biomass phenology (adjusted for year effect as described above) which was done by combining all three available years and subsequently Gaussian curve fitting (for each of the six tree species separately). We then calculated the available caterpillar biomass for all 621 flycatchers territories
Fig. 4 Number of fledglings per brood through the breeding season for collared (a) and pied flycatchers (b) on Öland. Fitted curves are derived from a GLM (see Table 3)

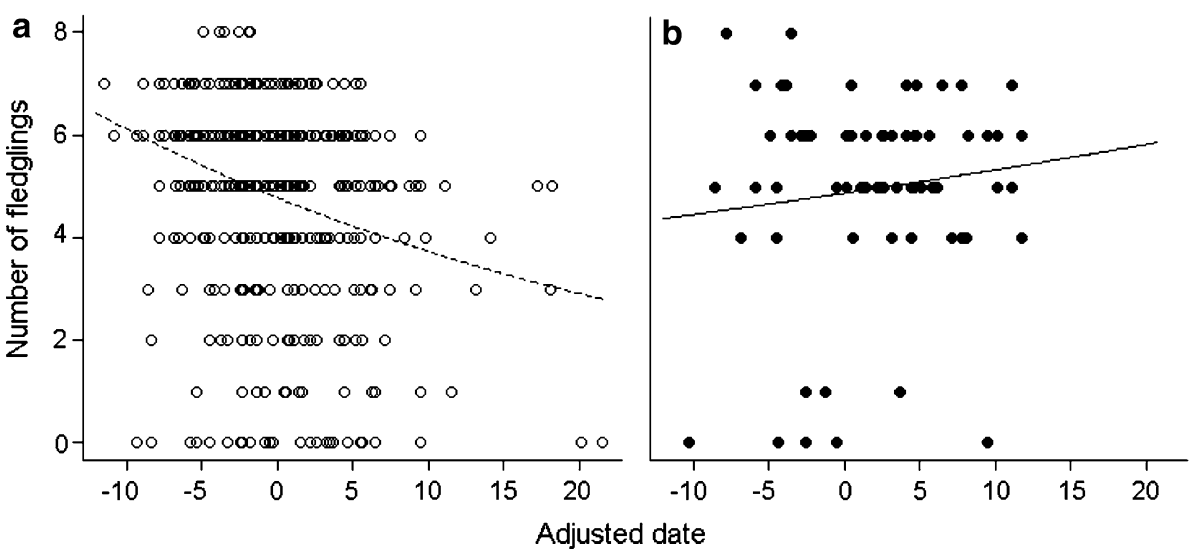




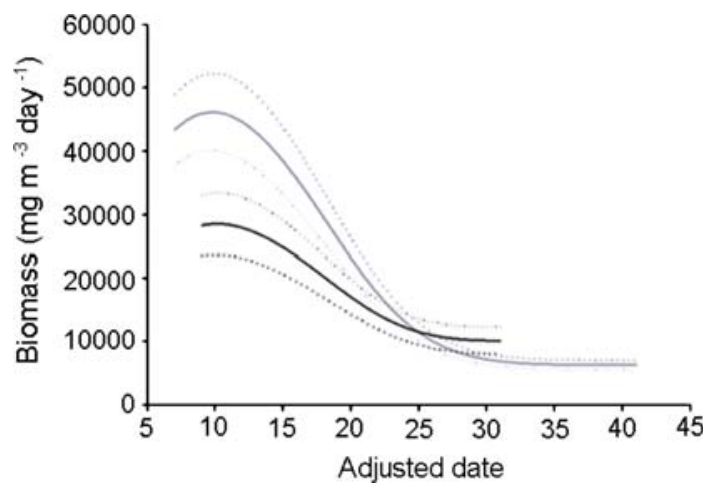

Fig. 5 Caterpillar biomass against adjusted date for typical collared (solid grey lines) and pied flycatcher (solid black lines) territories. Dashed lines are \pm SE. This variation results from variation in habitat characteristics within territories of each species. See text for details on the calculations and data inclusion

(see above for details). Note that the biomass now depends only on hatching date and species, not on the specific characteristics of a single territory, nor year.

The predicted caterpillar biomass in relation to adjusted date is presented in Fig. 5. The variation in predicted biomass resulting from differences in habitat characteristics between territories of conspecific flycatchers is represented by SEs (Fig. 5, dashed lines) and was calculated using SE propagation rules. A similar steep decline as in the 20032004 subset (Fig. 3) is found for the collared flycatcher, but the results for the pied flycatcher differ as the caterpillar biomass also declines for this species through the season, although less severely compared with the collared flycatcher.

In the analysis of 2003-2004 data, we did find a pattern of predicted caterpillar biomass through the season which seemed consistent with the finding that the reproductive success of the pied flycatchers shows no seasonal decline (it in fact marginally increased towards the end of the season; Fig. 4); however, the reproductive success of the collared flycatcher did not show the seasonal decline in the subset we set out to explain.

The final step is to link the predicted caterpillar biomass with reproductive success.

We expected that the measure of food available should be positively associated with reproductive success. We analysed the relationship between caterpillar biomass and reproductive success using a GLM with quasi Poisson errors including year, species, log caterpillar biomass and an interaction between the latter two. Year was excluded first $\left(F_{1,616}=0.548, P=0.460\right)$, but subsequent removal of the interaction between species and log caterpillar biomass significantly reduced the model fit $\left(F_{1,617}=7.393\right.$ $P=0.007$ ); the interaction is depicted in Fig. 6. Analysing both species separately revealed a significant positive slope

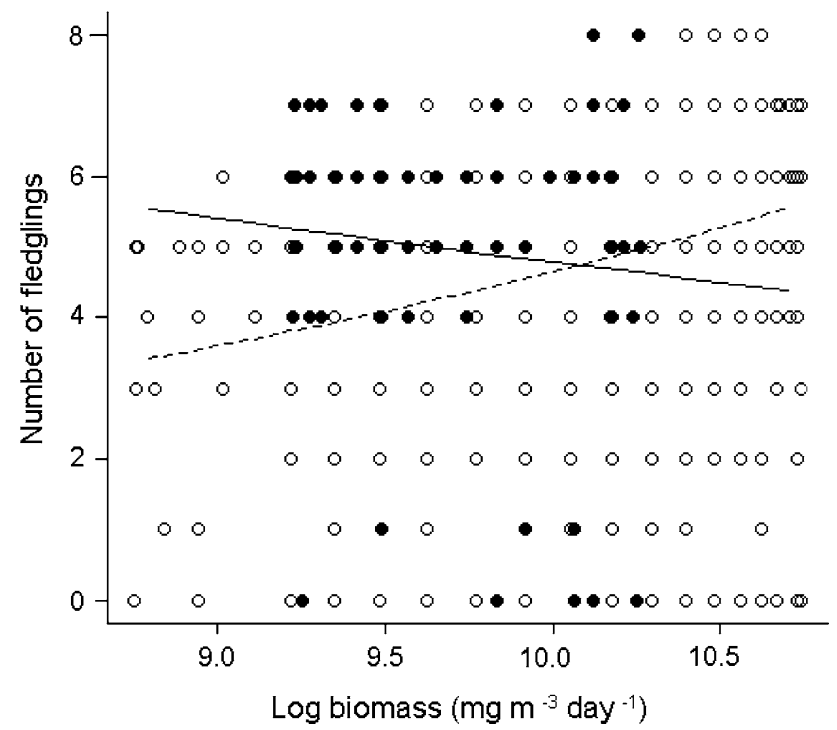

Fig. 6 The number of fledged young of collared (open circles) and pied flycatcher (solid circles) broods against the log caterpillar biomass available during the nestling period. The curves are derived from a GLM with quasi Poisson errors and represent a significant interaction between caterpillar biomass and species [collared flycatcher (dashed curve), pied flycatcher (solid curve)]

for the collared flycatcher $(d f=1,541$, estimate $=0.588$, $t=6.476, P<0.001)$, but no significant deviation from a slope of 0 for the pied flycatcher $(d f=1,76$, estimate $=-0.284, t=-0.922, P=0.360)$. Hence, we can conclude that the reproductive success and predicted food abundance are positively correlated for the collared flycatcher, but that there is no significant correlation for the pied flycatcher (though note the smaller sample size for the latter). These results should, however, be treated as preliminary as the variation around habitat characteristics is very large (Table 1).

\section{Discussion}

We set out to examine a possible explanation for differences in reproductive success between collared and pied flycatchers through the breeding season. An earlier study (Wiley et al. 2007) indicated that the location of the territory is important and here we investigated whether habitat differences in territories of the two species could lead to temporal differences in abundance of an important food resource (caterpillars) which in turn might underlie the high reproductive success of pied flycatchers late in the breeding season on Öland. We found that tree species composition differed between territories of the two species such that those of pied flycatchers consisted of more coniferous tree species (sensu Alerstam et al. 1978). Coniferous species had a much later peak of caterpillar abundance compared to 
deciduous species, leading to a significantly different pattern of predicted caterpillar biomass through the breeding season in pied flycatcher territories (no decline) compared to those of collared flycatchers (steep decline) for the 20032004 data (for which we have detailed information). The pattern is different when using all available data (20022007) as pied flycatchers also showed a decline through the season, though less steep. The final step revealed a significant correlation between predicted caterpillar biomass and reproductive success for the collared flycatcher over all years combined, which is to be expected when caterpillars are an important food resource. However, caterpillar biomass was not linked to reproductive success for the pied flycatcher. We will discuss several possible explanations for these results.

The first explanation for the lack of correlation between caterpillar biomass and reproductive success of pied flycatchers is that this species may switch to different food resources late in the breeding season. A previous study on Öland (Wiley et al. 2007) found a change in diet through the season such that the proportion of caterpillar decreased through the season. Other studies have shown that larvae of other taxa increase in abundance later in the season, especially in coniferous forests (Veistola et al. 1995, 1997; Eeva et al. 2005). Caterpillars accounted for a smaller proportion of the pied flycatcher diet in coniferous habitat compared to deciduous [15.6\% $(\mathrm{SD}=10.1)$ and $34.2 \% \quad(\mathrm{SD}=21.4)$ respectively; data from Cramp and Perrins (1993)]. A similar difference was found for Lepidoptera abundance in collared flycatcher diets in the Czech Republic [coniferous $13.1 \%$ and deciduous 20.8\% (Bureš 1995; Bureš and Stríteský 1996)].

In our sampling approach, only frass of a subset of larvae available to flycatchers was collected, which therefore biased the estimate of food availability as it did not include any other food resource. Although caterpillars make up a substantial part of the flycatchers' diet, it is important to incorporate the other food resources as well in order to get a better understanding of the potential effect of temporal differences in food availability. Small effects of many resources may add up to have a large effect on reproductive success. The set-up of future studies investigating such effects could be improved upon over our approach by increasing the number of sampling locations and locating these within breeding territories to reduce any potential site effects. A general problem with using dietary data of other studies as mentioned above (including Wiley et al. 2007) is that they used the number of prey items and not the biomass, which makes it problematic to compare these data directly with our data.

A second possible explanation is that the increase in caterpillar biomass in coniferous species through the breeding season is indeed important, but was not captured by the approach used in this study. Several studies have indicated benefits arising from utilising coniferous forest later in the breeding season, such as higher fledgling weights found in great tits (van Balen 1973). Furthermore, great tit family groups (parents with fledged offspring) switched to feeding in coniferous habitat later in the breeding season (Verboven et al. 2001). One of several reasons why we may not have picked up the advantages of utilising coniferous forest is that caterpillars in coniferous habitat are more easily available (e.g. are bigger and more conspicuous) compared to in deciduous habitat later in the season, resulting in increased feeding efficiency.

The flycatcher species may differ in their ability to feed in coniferous woodland, e.g. due to differences in body size (Forstmeier et al. 2001; Korner-Nievergelt and Leisler 2004). The pied flycatcher indeed appears to be better at foraging in coniferous environments as shown in a recent experimental study (Adamik and Bureš 2007). More detailed knowledge of the ecology of flycatchers is needed to quantify the relative impact of these factors on reproductive success and ultimately coexistence.

Moreover, trying to link habitat differences to reproductive success inherently means using several indirect measures. For example, we used caterpillar frass to estimate caterpillar biomass. Furthermore, the relation between measured food availability and nestling requirements is assumed to be continuous. However, caterpillars might be available in excess during the food peak and only influence reproductive success once dropping under a certain minimum threshold. We explored this idea by calculating caterpillar abundance only during the period of highest nestling demand [9-15 days (Lundberg and Alatalo 1992)]. However, this did not qualitatively change our results (analysis not presented). Using several steps (from habitat measures, through caterpillar biomass to reproductive success) will increase the variance of the derived explanatory variable (caterpillar biomass) and reduces the possibility to detect weak effects. The reproductive success of flycatchers is not only determined by food availability; for example weather conditions are very important (personal observation), as well as additional effects that are intrinsic to the parents (e.g. age). Our finding that reproductive success does not decline for collared flycatcher in 2003-2004 indicates that other factors are likely to have an important influence on reproductive success and should be taken into account in future studies.

The coexistence of the two flycatcher species will be influenced by many different factors. The secondary contact zone on the Baltic islands is probably relatively young and the system might not be at equilibrium. The contact zone in central Europe, however, appears to be in (near) equilibrium (e.g. Sætre et al. 1999a) and qualitatively similar habitat occupation patterns are found on Öland, although these 
are less pronounced due to geographical differences. Longterm data suggest a decrease in pied flycatcher abundance but this appears to level off (Qvarnström et al. 2009 and references therein) and does not match rapid competitiveexclusion events as found between e.g. Townsend's (Dendroica townsendi) and hermit warblers (D. occidentalis; Owen-Ashley and Butler 2004). We studied competition between the species during the breeding season, a period in which reproductive success depends on both intraspecific (Török and Tóth 1988) and interspecific competition (e.g. Gustafsson 1987 but see Török and Tóth 1988). However, selection in the non-breeding season might also influence coexistence. The two flycatcher species have distinct wintering quarters (Veen et al. 2007), ruling out strong competition between these two species in winter. However, pied flycatchers might suffer more during the non-breeding period as indicated by higher mortality of first-year migrants (Veen et al. 2007). On the other hand, the pied flycatcher populations on the Baltic Islands receive more immigrants. Lastly, the observed differences in habitat might simply result from differences in arrival dates and territory occupancy. Both ringing data (from southern Gotland between 1977 and 1992) and personal observations indicate that these species arrive synchronously.

In conclusion, habitat characteristics are predicted to lead to temporal differences in caterpillar abundance, which negatively correlated with the reproductive success of collared but not pied flycatchers. This will facilitate coexistence, but other factors, such as differences in adaptation to harsh environments, are most likely to be equally (or more) important.

Acknowledgments We would like to thank Lars Gustafsson and Johan Träff for granting access to work in their nest-box areas. We are grateful to Jukka Forsman, Nina Svedin and especially Mårten B. Hjernquist for providing help in the field and making their data accessible, and to Tore Schweder, Chris Wiley, Niclas Vallin, Joost Tinbergen, two anonymous reviewers and the editor for very helpful advice. Financial support was obtained from the Netherlands Organization for Scientific Research (grant NWO-ALW 812.04.001 to T. V.), Marie Curie EST grant (MEST-CT-2005-020932 to T. V.), the Swedish Research Council (A. Q.), FORMAS (A. Q.) and the Royal Swedish Academy of Science (A. Q.). This study was performed in accordance with Swedish law.

Open Access This article is distributed under the terms of the Creative Commons Attribution Noncommercial License which permits any noncommercial use, distribution, and reproduction in any medium, provided the original author(s) and source are credited.

\section{References}

Adamik P, Bureš S (2007) Experimental evidence for species-specific habitat preferences in two flycatcher species in their hybrid zone. Naturwissenschaften 94:859-863

Alerstam T, Ebenman B, Sylven M, Tamm S, Ulfstrand S (1978) Hybridization as an agent of competition between 2 bird allospe-
cies-Ficedula albicollis and F. hypoleuca on the island of Gotland in the Baltic. Oikos 31:326-331

Bureš S (1995) Comparison of diet in collared flycatcher (Ficedula albicollis) and pied flycatcher (Ficedula hypoleuca) nestlings in a hybrid zone. Folia Zool 44:247-253

Bureš S, Stř́iteský J (1996) Diet of collared flycatcher (Ficedula albicollis) in spruce forest. Zprávy MOS 54:75-78

Chesson P (2000) Mechanisms of maintenance of species diversity. Annu Rev Ecol Syst 31:343-366

Cody ML (1978) Habitat selection and interspecific territoriality among the Sylviid warblers of England and Sweden. Ecol Monogr 48:351-396

Cramp S, Perrins CM (1993) The Birds of the Western Palearctic. Oxford University Press, Oxford

Crawley MJ (2007) The R book. Wiley, Chichester

Edwards TC, Collopy MW (1988) Nest tree preference of ospreys in northcentral Florida. J Wildl Manage 52:103-107

Eeva T, Lehikoinen E, Pohjalainen T (1997) Pollution-related variation in food supply and breeding success in two hole-nesting passerines. Ecology 78:1120-1131

Eeva T, Ryoma M, Riihimaki J (2005) Pollution-related changes in diets of two insectivorous passerines. Oecologia 145:629-639

Forstmeier W, Bourski OV, Leisler B (2001) Habitat choice in Phylloscopus warblers: the role of morphology, phylogeny and competition. Oecologia 128:566-576

Gustafsson L (1987) Interspecific competition lowers fitness in the collared flycatcher Ficedula albicollis: an experimental demonstration. Ecology 68:291-296

Hardin G (1960) Competitive exclusion principle. Science 131:12921297

Hudman SP, Chandler CR (2002) Spatial and habitat relationships of red-eyed and blue-headed vireos in the southern Appalachians. Wilson Bull 114:227-234

Huhta E, Jokimäki J, Rahko P (1998) Distribution and reproductive success of the pied flycatcher Ficedula hypoleuca in relation to forest patch size and vegetation characteristics; the effect of scale. Ibis 140:214-222

Korner-Nievergelt F, Leisler B (2004) Morphological convergence in conifer-dwelling passerines. J Ornithol 145:245-255

Lundberg A, Alatalo RV (1992) The pied flycatcher. Poyser, London

Lundberg A, Alatalo RV, Carlson A, Ulfstrand S (1981) Biometry, habitat distribution and breeding success in the pied flycatcher Ficedula hypoleuca. Ornis Scand 12:68-79

Owen-Ashley NT, Butler LK (2004) Androgens, interspecific competition and species replacement in hybridizing warblers. Proc R Soc Lond Ser B Biol Sci 271:S498-S500

Perrins CM (1970) Timing of birds' breeding seasons. Ibis 112:242255

Qvarnström A, Svedin N, Wiley C, Veen T, Gustafsson L (2005) Cross-fostering reveals seasonal changes in the relative fitness of two competing species of flycatchers. Biol Lett 1:68-71

Qvarnström A, Wiley C, Svedin N, Vallin N (2009) Life-history divergence facilitates regional coexistence of competing Ficedula flycatchers. Ecology 90:1948-1957

Sætre GP, Kral M, Bureš S, Ims RA (1999a) Dynamics of a clinal hybrid zone and a comparison with island hybrid zones of flycatchers (Ficedula hypoleuca and F. albicollis). J Zool 247:53-64

Sætre GP, Post E, Kral M (1999b) Can environmental fluctuation prevent competitive exclusion in sympatric flycatchers? Proc R Soc Lond Ser B Biol Sci 266:1247-1251

Sætre GP, Borge T, Lindroos K, Haavie J, Sheldon BC, Primmer C, Syvanen AC (2003) Sex chromosome evolution and speciation in Ficedula flycatchers. Proc R Soc Lond Ser B Biol Sci 270:53-59

Siikamäki P (1998) Limitation of reproductive success by food availability and breeding time in pied flycatchers. Ecology 79:1789-1796 
R Development Core Team (2008) R: a language and environment for statistical computing. R Foundation for Statistical Computing, Vienna

Tinbergen L (1960) The natural control of insects in pine woods. I: factors influencing the intensity of predation by song birds. Arch Neerl Zool 13:265-336

Tinbergen JM, Dietz MW (1994) Parental energy-expenditure during brood rearing in the great tit (Parus major) in relation to bodymass, temperature, food availability and clutch size. Funct Ecol $8: 563-572$

Török J, Tóth L (1988) Density dependence in reproduction of the collared flycatcher (Ficedula albicollis) at high population levels. J Anim Ecol 57:251-258

van Balen JH (1973) Comparative study of breeding ecology of great tit Parus major in different habitats. Ardea 61:1-93

Veen T, Borge T, Griffith SC, Sætre GP, Bureš S, Gustafsson L, Sheldon BC (2001) Hybridization and adaptive mate choice in flycatchers. Nature 411:45-50

Veen T, Svedin N, Forsman JT, Hjernquist MB, Qvarnström A, Thuman Hjernquist KA, Träff J, Klaassen M (2007) Does migration of hybrids contribute to post-zygotic isolation in flycatchers? Proc R Soc Lond Ser B Biol Sci 274:707-712
Veistola S, Eeva T, Lehikoinen E (1995) Seasonal occurrence of arthropods as a source of food for birds in Finnish Lapland. Entomol Fenn 6:177-181

Veistola S, Lehikoinen E, Eeva T (1997) Foraging niches of two passerines at their subarctic limit of distribution: the Siberian tit Parus cinctus and the pied flycatcher Ficedula hypoleuca. Ornis Fenn 74:79-87

Verboven N, Tinbergen JM, Verhulst S (2001) Food, reproductive success and multiple breeding in the great tit Parus major. Ardea 89:387-406

Verner J, Larson TA (1989) Richness of breeding bird species in mixed-conifer forests of the Sierra-Nevada, California. Auk 106:447-463

Visser ME, Holleman LJM, Gienapp P (2006) Shifts in caterpillar biomass phenology due to climate change and its impact on the breeding biology of an insectivorous bird. Oecologia 147:164 172

Wiley C, Fogelberg N, Saether SA, Veen T, Svedin N, Vogel Kehlenbeck J, Qvarnström A (2007) Direct benefits and costs for hybridizing Ficedula flycatchers. J Evol Biol 20:854-864

Wright SJ (2002) Plant diversity in tropical forests: a review of mechanisms of species coexistence. Oecologia 130:1-14 